pregnancy. Biochem J 156:357

18. Kalkhoff RK, Hissebah AM, Hak-Joong K 1978 Carbohydrate and lipid metabolism during normal pregnancy: relationship to gestational hormone action. Sem Perinatol 2:291

19. Kervran A, Rieutort M, Guillaume M 1976 A simultaneous radioimmunoassay for growth hormone and insulin in the plasma of rats and rabbits. Diabetes Metab 2:67

20. Knopp RH, Saudek CD, Arky RA, O'Sullivan JB 1973 Two phases of adipose tissue metabolism in pregnancy: maternal adaptation for fetal growth. Endocrinology 92:984

21. Lebas F 1975 Etude chez la lapine de l'influence du niveau d'alimentation durant la gestation. Ann Zootech. 24:267

22. Leturque A, Ferre P, Satabin P, Kervran A, Girard J 1980 In vivo insulin resistance during pregnancy in the rat. Diabetologia 19:521

23. Leturque A, Gilbert M, Girard J 1981 Glucose turnover during pregnancy in anesthetized post-absorptive rats. Biochem J 196:633

24. Lopez-Quijada C, Gomez Acebo J, Candela JLR 1967 Decrease in the insulin of rabbit pancreas in late pregnancy. Diabetologia 3:435

25. Maurer RR, Hunt WL, Foote RH 1968 Repeated superovulation following administration of exogenous gonadotrophins in Dutch-belted rabbits. J Reprod Fert 15:93

26. McDonald-Gibson RG, Young M, Hytten FE 1975 Changes in plasma esterified fatty acids and serum glycerol in pregnancy. $\mathrm{Br} J$ Obstet Gynecol 82:460

27. Metzger BE, Hare JW, Freinkel N 1971 Carbohydrate metabolism in pregnancy. IX. Plasma levels of gluconeogenic fuels during fasting in the rat. $J$ Clin Endocrinol Metab 33:869

28. Metzger BE, Unger RH, Freinkel N 1977 Carbohydrate metabolism in pregnancy. XIV. Relationships between circulating glucagon, insulin, glucose and amino acids in response to a "mixed meal" in late pregnancy. Metabolism 26:151

29. Perrson B, Lunell NO 1975 Metabolic control in diabetic pregnancy. Am J Obstet Gynecol 122:737
30. Phelps RL, Metzger BE, Freinkel N 1981 Carbohydrate metabolism in pregnancy. XVII. Diurnal profiles of plasma glucose, insulin, free-fatty acids, triglycerides, cholesterol and individual amino acids in late normal pregnancy. Am J Obstet Gynecol 140:730

31. Pitkin RM 1977 Obstetrics and gynecology. In: Schneider HA, Anderson CE, Coursin DB (eds) Nutritional Support of Medical Practice. Harper and Row, New York, pp 407-421

32. Saudek CD, Finkowski M, Knopp RH 1975 Plasma glucagon and insulin in rat pregnancy. Roles in glucose homeostasis. J Clin Invest 55:180

33. Scow RO, Chernick SS, Brinley MS 1964 Hyperlipemia and ketosis in the pregnant rat. Am J Physiol 206:796

34. Silverstone FA, Solomon E, Rubricius J 1961 The rapid intravenous glucose tolerance test in pregnancy. $\mathrm{J}$ Clin Invest 40:2180

35. Sparks JW, Hay WW Jr, Meschia G, Battaglia FC 1982 Lactate production and utilization rates in the lamb fetus in vivo. J Clin Invest 70:179

36. Sparks JW, Johnson R, Block S, Hay WW Jr, Meyers S, Meschia G, Battaglia FC 1982 Comparative physiology of the pregnant chronically catheterized sheep, guinea pig and rabbit. Fed Proc 41:1376 (Abstr 6463)

37. Sparks JW, Pegorier JP, Girard J, Battaglia FC 1981 Substrate concentration changes during pregnancy in the guinea pig studied under unstressed steady state conditions. Pediatr Res 15:1340

38. Strubbe JH, Gorissen J 1980 Meal patterning in the lactating rat. Physiol Behav 25:775

39. Sutter-Dub MT, Leclercq R, Felix JM, Jacquot R, Sutter BCJ 1973 Serum progesterone and immunoreactive insulin levels in the pregnant rat. Horm Metab Res 5:18

40. Unger R, Orci L 1981 Glucogon and the A cell. Physiology and pathophysiology. N Engl J Med 304:1518

41. Victor AL 1974 Normal blood sugar variation during pregnancy. Acta Obstet Gynecol Scand 53:37

42. Zilversmit DB, Hughes LB, Remington M 1972 Hypolipidemic effect of pregnancy in the rabbit. J Lipid Res 13:750

\title{
Vasodilators and Ventricular Septal Defect: Comparison of Prazosin, Minoxidil, and Hydralazine in a Chronic Lamb Model
}

\author{
MARK M. BOUCEK, RICHARD CHANG, AND DAVID P. SYNHORST \\ Department of Pediatrics, Division of Pediatric Cardiology, University of Utah College of Medicine and Primary \\ Children's Medical Center, Salt Lake City, Utah 84132
}

\begin{abstract}
Summary
The volume overloading of the left ventricle which results from left to right (L-R) shunting through a ventricular septal defect (VSD) may be reduced by pharmacologic agents which lower systemic vascular resistance $\left(R_{s}\right)$ in excess of pulmonary arteriolar vascular resistance $\left(R_{\mathrm{pa}}\right)$. To study agents capable of decreasing the $L-R$ shunt through systemic vasodilatation, we created a chronic lamb model with VSD and administered three vasodilators, prazosin $(0.05 \mathrm{mg} / \mathrm{kg})$, hydralazine $(0.75 \mathrm{mg} / \mathrm{kg})$, and $\mathrm{mi}-$ noxidil ( $0.25 \mathrm{mg} / \mathrm{kg})$. Prazosin increased the $\mathbf{R}_{\mathrm{pa}}$ while lowering $R_{s}$, resulting in an increase in $R_{p a} / R_{s}$ by $43 \%(p \leqslant 0.005)$. Prazosin decreased the pulmonary flow $\left(\dot{Q}_{p}\right)$ slightly, decreased L-R shunt by $16 \%$, reduced the pulmonary to systemic flow ratio

Received July 25, 1983; accepted February 7, 1984

Correspondence may be addressed to Mark M. Boucek, M.D., Division of Pediatric Cardiology, Room 2B-415, University of Utah College of Medicine, Salt Lake City, UT 84132.

This work was supported in part by United States Public Health Service Grants HL21203 and HL27802 and The Thrasher Research Fund.
\end{abstract}

$\left(\dot{Q}_{\mathrm{p}} / \dot{\mathrm{Q}}_{\mathrm{s}}\right)$ by $22 \%(p \leqslant 0.005)$, and lowered the left atrial mean pressure (LA) by $16 \%(p \leqslant 0.005)$ with no effect on heart rate. Hydralazine lowered the $R_{p a}$ and $R_{s}$ equally and thus did not change the $R_{p a} / R_{s}$ or the volume of $L-R$ shunt (7.6 versus 8.1 liters $/ \mathrm{min} / \mathrm{m}^{2}$ ). No change in $\overline{\mathrm{LA}}$ was seen with hydralazine but heart rate increased from 162 to $200 / \mathrm{min}(p \leqslant 0.01)$. Minoxidil did not change the $L-R$ shunt $\left(6.9\right.$ versus $\left.6.8 \mathrm{liters} / \mathrm{min} / \mathrm{m}^{2}\right)$ and, in general, produced effects intermediate between prazosin and hydralazine. The data support a selective systemic vasodilation with prazosin, a property not shared by either minoxidil or hydralazine, which results in a reduction of shunting and left ventricular volume overloading in lambs with VSD. Furthermore, since prazosin did not decrease the pulmonary resistance, the data indicate that the elevation in pulmonary resistance in lambs with VSD is not mediated by the $\alpha_{1}$-adrenergic receptor.

\section{Abbreviations}

VSD, ventricular septal defect

$\mathbf{R}_{\mathrm{pa}}$, pulmonary arteriolar vascular resistance 
$R_{s}$, systemic vascular resistance

L-R, left to right

$\dot{\mathrm{Q}}_{\mathrm{p}} / \dot{\mathrm{Q}}_{\mathrm{s}}$ ratios, pulmonary to systemic blood flow ratios

$\overline{\mathrm{Ao}}$, mean aortic pressure

BSA, body surface area

The amount of left to right shunting found in the presence of a large VSD is determined largely by the ratio of $R_{p a}$ to $R_{s}$. Pharmacologic manipulation of these vascular beds may increase the $R_{p a} / R_{s}$ ratio and reduce interventricular shunting and volume overloading of the left ventricle. The mechanisms by which pulmonary arteriolar resistance is regulated in the presence of a left to right shunt at the ventricular level are unknown. These controlling mechanisms would appear to be important in determining the clinical course of patients with such defects and in optimizing their medical management. Studies with acute animal VSD models have suggested that vasodilators may decrease $L-R$ shunting $(28,30)$, although these studies may be limited by the use of acutely prepared, open chested animals. This study utilized a chronically instrumented lamb model of ventricular septal defect to evaluate the effects of three vasoactive agents in the awake, erect animal.

Ventricular septal defect is the most common congenital heart defect (13) and affected children may develop symptoms of congestive heart failure for which traditional management with digoxin and diuretics is often ineffective (29). Surgical intervention in small, ill infants may have a higher mortality than if pharmacologic treatment allows the child to grow prior to operation (11). Additionally, effective pharmacologic treatment of these patients may allow the defect to become smaller or close spontaneously as the child grows $(6,14)$.

We evaluated the effect of three clinically available vasodilators, prazosin, hydralazine, and minoxidil, on the hemodynamics found in a chronic lamb model of ventricular septal defect in order to determine if any of these agents showed vascular selectivity.

\section{MATERIALS AND METHODS}

Infant lambs ( $<2$ weeks old) weighing 5 to $8 \mathrm{~kg}$ were anesthetized with $20 \mathrm{mg} / \mathrm{kg}$ of intramuscular ketamine. They were intubated and ventilated and a right thoracotomy was performed. The right atrial appendage was encircled with a purse-string suture and the lamb was given $2 \mathrm{mg} / \mathrm{kg}$ of intravenous lidocaine to prevent ventricular fibrillation when the grommet was inserted. A modification of the instrument described by Synhorst et al. (28) was used to pass a plastic grommet through the right atrial appendage, across the tricuspid valve, and near to the apex of the right ventricle. The tip of the instrument and the grommet were forced across the muscular interventricular septum. The instrument was removed and the grommet remained in the interventricular septum with the flanges on either end holding it in place. The internal diameter of the hole between the right and left ventricles was $8 \mathrm{~mm}$ which resulted in right ventricular systolic pressures which were approximately $50 \%$ of those in the left ventricle. The $\dot{\mathrm{Q}}_{\mathrm{p}} / \dot{\mathrm{Q}}_{\mathrm{s}}$ ratios were routinely greater than 3:1.

Approximately 1 week after the initial procedure, the lambs were again anesthetized and the ascending aorta and main pulmonary artery were exposed through a left thoracotomy. An electromagnetic flow probe (Biotronix, Inc.) of $12 \mathrm{~mm}$ internal diameter was placed around the ascending aorta and a probe of 14-16 mm was placed on the main pulmonary artery. Catheters were secured in the main pulmonary artery and left atrium and the proximal end of the catheters and the flow probe cables were tunneled subcutaneously to exit at the back of the neck. An aortic catheter was placed via the carotid artery and in several animals a right atrial catheter was placed via the internal jugular vein. Each of the catheters was filled with concentrated heparin. The flow probe connectors and stopcocks on the end of the left atrial pulmonary artery and aortic pressure lines which were exposed at the posterior base of the neck were wrapped carefully to prevent damage by the lamb. The lambs were allowed to recover for 1 week prior to the beginning of data collection.

Each flow probe was calibrated with saline, prior to implantation, on a blood vessel similar in size to the actual vessels over the range of flow expected for the animal. The implanted probes were periodically compared to Fick-determined estimates of the pulmonary to systemic flow ratio. Zero flow was determined for each data collection at end-diastole. A Biotronix 613 flowmeter was interfaced with a Honeywell model 1912 Viscicorder and both phasic and mean flow were recorded. Catheters were attached to Statham P23 DB transducers and the pressures were displayed and recorded with the aid of a Honeywell $135 \mathrm{D} / \mathrm{C}$ amplifier. The electrocardiogram was recorded with a Tectronix 412 monitor.

Drug administration. The drugs were infused via the pulmonary artery catheter over several minutes. On any given day, only one drug or sham infusion was given to a lamb. Prazosin was dissolved in distilled water with warming and the volume infused was always less than $2 \mathrm{ml}$. The dose of prazosin used for all animals was $0.05 \mathrm{mg} / \mathrm{kg}$. Minoxidil was dissolved in a fashion similar to prazosin and given to the lambs in a dose of $0.25 \mathrm{mg} /$ $\mathrm{kg}$. The drugs were weighed and prepared fresh on the day of use and were passed through a $0.45-\mu$ Millipore filter prior to use in order to sterilize the solutions. Hydralazine was given in a dose of $0.75 \mathrm{mg} / \mathrm{kg}$ and the intravenous preparation was obtained from the hospital pharmacy. The approximate dose for each drug was determined from published values $(8,10,23)$. The dose was then adjusted in initial studies in two lambs to produce the maximum reduction in $R_{s}$ without changing $\overline{\mathrm{Ao}}$.

Data collection. The lambs were studied while standing quietly in a supporting cradle. Control data were collected after a 30min stabilization period and the lamb was then given either a drug infusion or a sham drug administration using a like volume of distilled water. Aortic, pulmonary artery, and left atrial pressures and phasic and mean aortic and pulmonary artery flows were recorded every $15 \mathrm{~min}$. Heart rate was monitored continuously. "Cross-talk" between the flow probes was excluded since only one probe was energized at any given time. Six animals were included in each drug group. The lambs were 4-5 weeks of age at the time of data collection, were ambulatory, and were feeding normally. The hemoglobin values with this model ranged from $10-13 \mathrm{~g} / \mathrm{dl}$; the $\mathrm{pH}$ and arterial blood gases were within the normal range for this altitude $\left(\mathrm{PO}_{2} 50-70\right.$ torr).

Data reduction. BSA was calculated using the formula $\mathrm{BSA}=$ $0.121 \times(\mathrm{kg})^{2 / 3}(18)$. Flow and resistance data were indexed to body surface area. The data obtained immediately prior to drug administration were used as control values. To eliminate differences in time of onset of action, the data obtained at the maximal reduction of systemic vascular resistance were used to compare the effect of one drug to another.

The L-R shunt was determined by subtracting the $\dot{Q}_{s}$ from the $\dot{Q}_{p}$. The total pulmonary resistance index $\left(R_{p}\right)$ was calculated according to the formula $R_{p}=\overline{P A} / \dot{Q}_{p}$, where $\overline{P A}$ is the mean pulmonary artery pressure. The total systemic resistance index $\left(R_{s}\right)$ was similarly calculated with the formula $R_{s}=\overline{\mathrm{Ao}} / \dot{Q}_{s}$, where $\overline{\mathrm{Ao}}$ is the mean aortic pressure, Pulmonary arteriolar resistance $\left(R_{p a}\right)$ was calculated by subtracting the mean left atrial pressure (LA) from the $\overline{\mathrm{PA}}$ and dividing by the $\dot{\mathrm{Q}}_{\mathrm{p}}$ according to the formula $\mathrm{R}_{\mathrm{pa}}=\overline{\mathrm{PA}}-\overline{\mathrm{LA}} / \dot{\mathrm{Q}}_{\mathrm{p}}$. All resistance values were indexed to the BSA and are expressed without units.

Statistics. The data were evaluated for statistical significance using Student's $t$ test for paired data since each animal served as its own control. Significant drug effect was defined as a change from control with a $p$ value less than 0.05 (27).

\section{RESULTS}

Stability of the model. The mean values of data collected from six animals prior to and following sham drug administration are 
shown in Figure 1. No significant change was observed in pressures, flows, or resistances over a 60 -min period. The largest variation from control was an insignificant $6 \%$ decrease in the $\dot{\mathrm{Q}}_{\mathrm{p}} / \dot{\mathrm{Q}}_{\mathrm{s}}$ ratio at $45 \mathrm{~min}$.

Prazosin. The intravenously administered prazosin $(0.05 \mathrm{mg} /$ $\mathrm{kg}$ ) caused a reduction in $R_{s}$ which reached a maximum $22 \%$ less than control at $30 \mathrm{~min}$. Increasing the dose of prazosin had no additional effect. At the time of maximal reduction of $R_{s}, R_{p a}$ was increased by $17 \%$ resulting in an increase in $R_{p a} / R_{s}$ of $43 \%$ $(p \leqslant 0.005)$. The $\dot{\mathrm{Q}}_{\mathrm{p}} / \mathrm{Q}_{\mathrm{s}}$ ratio was reduced $22 \%(3.15$ to $2.47 ; p$ $\leqslant 0.01)$ as one would expect with an increase in $R_{p a} / R_{s}$ ratio (Table 1). $\dot{Q}_{\mathrm{s}}$ increased by $0.6 \mathrm{liter} / \mathrm{min} / \mathrm{m}^{2}$ (Fig. 2). The left to right shunt volume $\left(\dot{\mathrm{Q}}_{\mathrm{L}-\mathrm{R}}\right)$ was decreased from 5.8 to 4.8 liters/ $\mathrm{min} / \mathrm{m}^{2}(16 \% ; p \leqslant 0.01)$. The mean left atrial pressure was lowered from 16.0 to $13.4 \mathrm{~mm} \mathrm{Hg}(16 \% ; p \leqslant 0.005)$. The heart rate was not significantly altered by prazosin and a small reduction in both mean aortic and mean pulmonary artery pressure was seen (Table 2).

Hydralazine. Hydralazine caused a significant decrease in $\mathbf{R}_{\mathrm{s}}$ but $R_{p a}$ decreased also and the ratio $R_{p a} / R_{s}$ did not change significantly. Since both the pulmonary and systemic vascular beds were dilated, both the $\dot{Q}_{p}$ and $\dot{Q}_{s}$ were increased (Fig. 3). At the time of maximal effect $(20 \mathrm{~min})$, the $\mathrm{Q}_{\mathrm{p}} / \mathrm{Q}_{\mathrm{s}}$ ratio was lowered $18 \%(3.54$ versus $2.91 ; p \leqslant 0.005)$ due to a slightly greater effect on the $R_{s}$ compared to the $R_{p a}$ and the fixed resistance of the restrictive VSD itself (Table 1). The $\mathrm{Q}_{\mathrm{L}-\mathrm{R}}$ was increased from 7.6

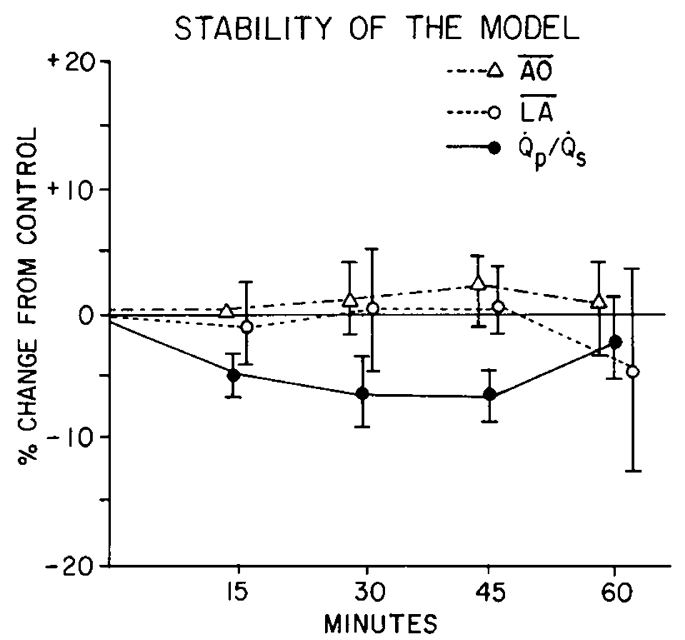

Fig. 1. Graphic display of the per cent change from control for the $\dot{\mathrm{Q}}_{\mathrm{p}} / \dot{\mathrm{Q}}_{\mathrm{s}}$, mean aortic $(\overline{B P})$ and left atrial $(\overline{L A})$ pressures, of six lambs given a sham drug infusion. Error bars indicate the standard error of the mean difference expressed as percentage of control. Experimental conditions were identical to actual drug infusions. None of the points were significantly different from control. to 8.1 liters $/ \mathrm{min} / \mathrm{m}^{2}(p \geqslant 0.05)$. The left atrial pressure was unchanged (19.3 versus $19.1 \mathrm{~mm} / \mathrm{Hg}$ ). The mean aortic pressure was unchanged and the mean pulmonary artery pressure decreased $4 \%$ (Table 2). In addition, a marked increase in heart rate from 162 to $200(p \leqslant 0.005)$ was seen. Increasing the dose of hydralazine to $1.5 \mathrm{mg} / \mathrm{kg}$ caused a significant reduction in $\overline{A o}$ and an increase in heart rate up to 240 .

Minoxidil. Minoxidil $(0.25 \mathrm{mg} / \mathrm{kg})$ produced the greatest reduction in $R_{s}(41 \%)$ but also reduced $R_{p a}$ by $39 \%$ resulting in only a $17 \%$ increase in $R_{p a} / R_{s}$ ratio. The maximal effect on $R_{s}$ occurred at $45 \mathrm{~min}$. The $\dot{\mathrm{Q}}_{\mathrm{p}} / \dot{\mathrm{Q}}_{\mathrm{s}}$ ratio was lowered $26 \%$ but included increases in both $\dot{Q}_{p}\left(9.8\right.$ to 11.8 liters $\left./ \mathrm{min} / \mathrm{m}^{2}\right)$ and $\dot{Q}_{s}$ (2.9 to 4.8 liters $/ \mathrm{min} / \mathrm{m}^{2}$ ) (Fig. 4). The $\dot{Q}_{\mathrm{L}-\mathrm{R}}$ was unchanged $(6.9$ to 7.07 liters $/ \mathrm{min} / \mathrm{m}^{2}$ ). There were insignificant changes in mean left atrial, aortic, and pulmonary artery pressures. Heart rate increased from 156 to $206(p \leqslant 0.05)$ (Table 2). Larger doses of minoxidil consistently lowered $\overline{\mathrm{AO}}$ and, like hydralazine, further increased the heart rate.

\section{DISCUSSION}

The ratio of pulmonary to systemic vascular resistance is important in determining the amount of left to right shunting which occurs in the presence of a large ventricular septal defect $(14,25,28)$. Pharmacologic agents which increase the ratio $R_{p a} /$

\section{PRAZOSIN vS TIME}

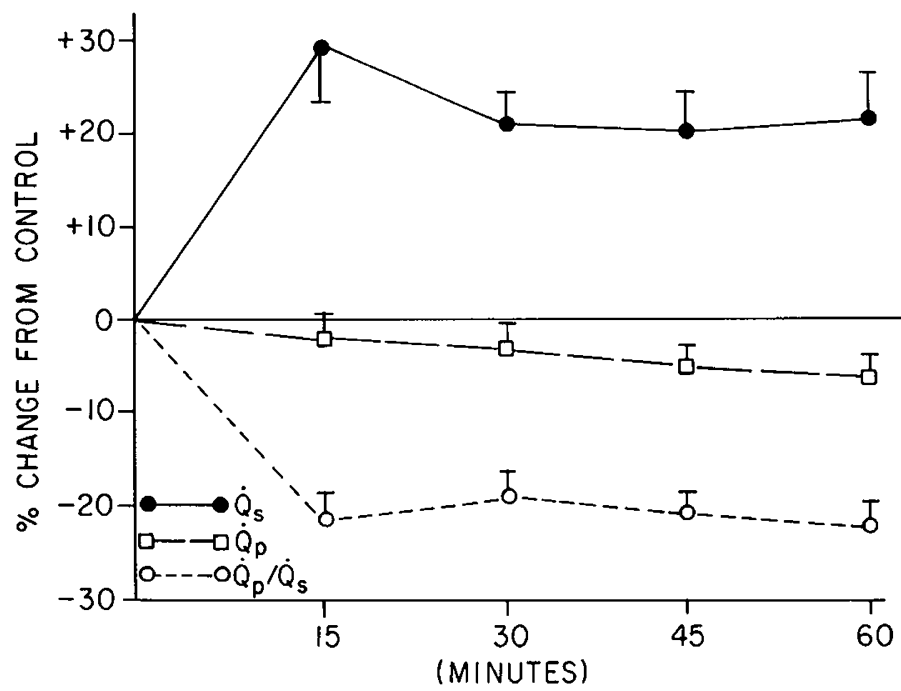

Fig. 2. The effect of prazosin $(0.05 \mathrm{mg} / \mathrm{kg})$ in per cent change from control versus time on the flow parameters of six lambs. Data are the mean values and error bars indicate the standard error of the mean difference expressed as percentage of control.

Table 1. Flow and resistance data and drug effect*

\begin{tabular}{|c|c|c|c|c|c|c|c|c|c|}
\hline & \multicolumn{3}{|c|}{ Prazosin } & \multicolumn{3}{|c|}{ Hydralazine } & \multicolumn{3}{|c|}{ Minoxidil } \\
\hline & Control & Max $\dagger$ & $\begin{array}{c}\% \\
\text { Change } \\
\end{array}$ & Control & $\operatorname{Max} \dagger$ & $\begin{array}{c}\% \\
\text { Change }\end{array}$ & Control & Max $†$ & $\begin{array}{c}\% \\
\text { Change }\end{array}$ \\
\hline$\dot{Q}_{\mathrm{s}}$ & $2.77 \pm .28$ & $3.37 \pm 0.31$ & $22 \ddagger$ & $2.93 \pm 0.19$ & $4.20 \pm 0.39$ & $30 \ddagger$ & $2.86 \pm 0.17$ & $4.75 \pm 0.39$ & $66 \ddagger$ \\
\hline$\dot{\mathrm{Q}}_{\mathrm{p}}$ & $8.59 \pm 0.95$ & $8.24 \pm 0.98$ & -4 & $10.49 \pm 1.08$ & $12.25 \pm 1.34$ & $15 \ddagger$ & $9.82 \pm 0.88$ & $11.81 \pm 0.88$ & $21^{\top}$ \\
\hline$\hat{\mathrm{Q}}_{\mathrm{p}} / \dot{\mathrm{Q}}_{\mathrm{s}}$ & $3.15 \pm 0.20$ & $2.47 \pm 0.17$ & $-22 \ddagger$ & $3.54 \pm 0.14$ & $2.91 \pm 0.15$ & $-18 \ddagger$ & $3.41 \pm 0.20$ & $2.52 \pm 0.21$ & $-26 \ddagger$ \\
\hline$\hat{\mathrm{Q}}_{\mathrm{L}-\mathrm{R}}$ & $5.83 \pm 0.73$ & $4.87 \pm 0.79$ & $-16 \ddagger$ & $7.61 \pm 0.91$ & $8.1 \pm 1.01$ & 7 & $6.95 \pm 0.75$ & $7.07 \pm 0.87$ & 2 \\
\hline$R_{p}$ & $3.31 \pm 0.25$ & $3.34 \pm 0.33$ & 1 & $3.15 \pm 0.26$ & $2.55 \pm 0.18$ & $-20 \ddagger$ & $3.31 \pm 0.44$ & $2.35 \pm 0.14$ & $-29 \ddagger$ \\
\hline $\mathrm{R}_{\mathrm{pa}}$ & $1.41 \pm 0.21$ & $1.65 \pm 0.24$ & 17 & $1.25 \pm 0.10$ & $0.92 \pm 0.14$ & $-27 \ddagger$ & $1.42 \pm 0.24$ & $0.87 \pm 0.18$ & $-39 \ddagger$ \\
\hline $\mathrm{R}_{\mathrm{s}}$ & $23.5 \pm 2.19$ & $18.2 \pm 1.90$ & $-22 \ddagger$ & $22.5 \pm 1.48$ & $15.7 \pm 0.99$ & $-35 \ddagger$ & $22.7 \pm 1.4$ & $13.4 \pm 1.08$ & $-41 \ddagger$ \\
\hline $\mathrm{R}_{\mathrm{pa}} / \mathrm{R}_{\mathrm{s}}$ & $0.067 \pm 0.014$ & $.096 \pm .016$ & $43 \ddagger$ & $.056 \pm .004$ & $.058 \pm .008$ & 3 & $.062 \pm .008$ & $.073 \pm .005$ & 17 \\
\hline
\end{tabular}

* Values are the mean $\pm \mathrm{SE}, n=6$.

$\dagger$ Data obtained at the time of maximum systemic vasodilitation. For prazosin, $30 \mathrm{~min}$; hydralazine, $20 \mathrm{~min}$; minoxidil, $45 \mathrm{~min}$.

$\ddagger p<0.05$ compared to control. 
Table 2. Mean pressure and heart rate and drug effect*

\begin{tabular}{|c|c|c|c|c|c|c|c|c|c|}
\hline & \multicolumn{3}{|c|}{ Prazosin } & \multicolumn{3}{|c|}{ Hydralazine } & \multicolumn{3}{|c|}{ Minoxidil } \\
\hline & Control & Maxt & $\begin{array}{c}\% \\
\text { Change } \\
\end{array}$ & Control & $\operatorname{Max} \dagger$ & $\begin{array}{c}\% \\
\text { Change }\end{array}$ & Control & $\operatorname{Max} \dagger$ & $\begin{array}{c}\% \\
\text { Change }\end{array}$ \\
\hline$\overline{\mathrm{LA}}$ & $15.9 \pm 1.6$ & $13.4 \pm 1.7$ & $-16 \ddagger$ & $19.3 \pm 1.6$ & $19.1 \pm 2.0$ & -1 & $17.8 \pm 2.7$ & $16.3 \pm 2.8$ & -8 \\
\hline$\overline{\mathrm{PA}}$ & $28.4 \pm 3.3$ & $26.8 \pm 3.0$ & -4 & $31.8 \pm 2.1$ & $29.8 \pm 2.1$ & -4 & $30.8 \pm 2.9$ & $27.7 \pm 3.0$ & -10 \\
\hline$\overline{\mathrm{AO}}$ & $61.7 \pm 1.6$ & $57.5 \pm 1.6$ & $-7 \ddagger$ & $64.3 \pm 1.1$ & $63.6 \pm 1.6$ & -1 & $63.9 \pm 1.9$ & $61.3 \pm 2.1$ & -4 \\
\hline HR & $159 \pm 9$ & $163 \pm 12$ & 3 & $162 \pm 7$ & $200 \pm 7$ & $24 \ddagger$ & $156 \pm 7$ & $206 \pm 10$ & $32 \ddagger$ \\
\hline
\end{tabular}

* Values are the mean $\pm \mathrm{SE}, n=6$.

$\dagger$ Data obtained at the time of maximum systemic vasodilitation (see Table 1).

$\ddagger p<0.05$ compared to control.

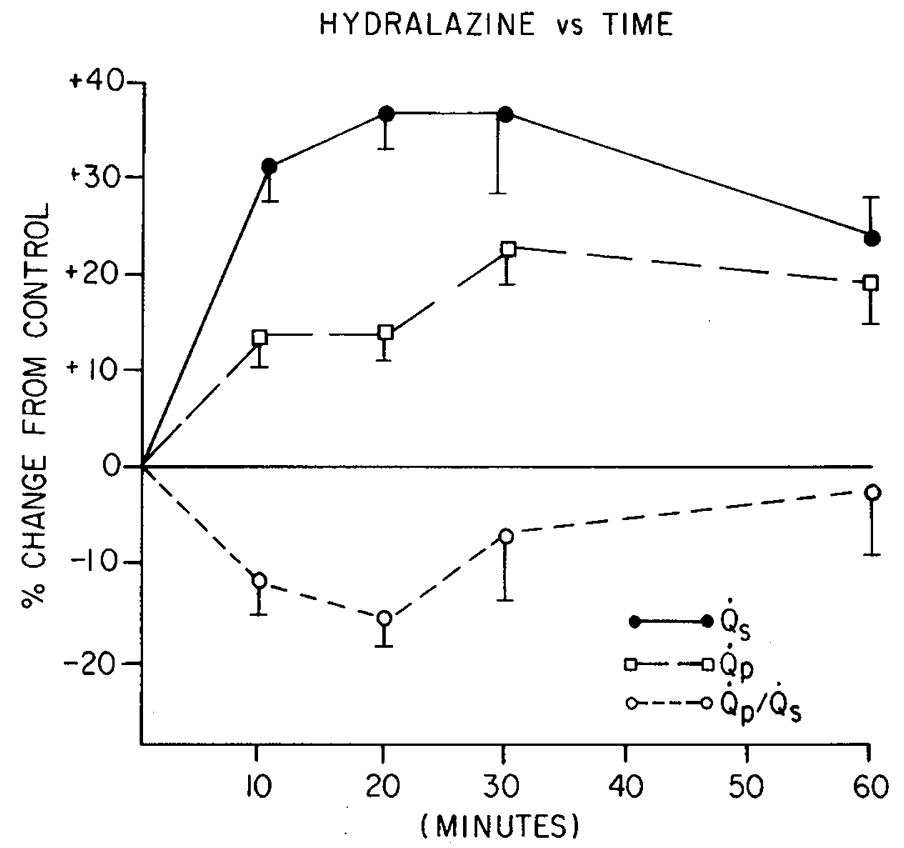

Fig. 3. The effect of hydralazine $(0.75 \mathrm{mg} / \mathrm{kg})$ in per cent change from control versus time on the flow parameters of six lambs. Data are the mean value and error bars indicate the standard error of the mean difference expressed as percentage of control.

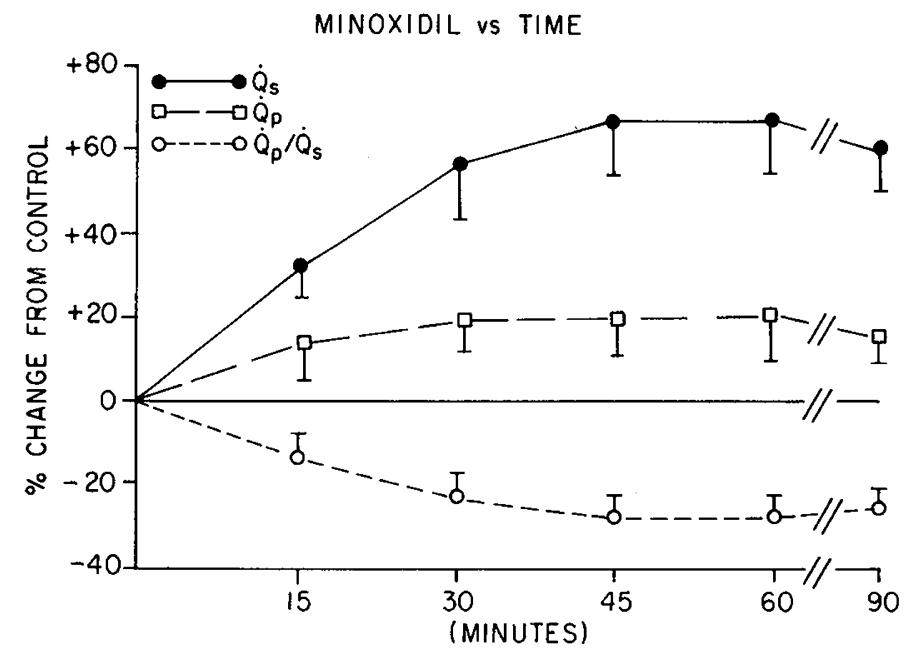

Fig. 4. The effect of minoxidil $(0.25 \mathrm{mg} / \mathrm{kg})$ in per cent change from control versus time on the flow parameters of six lambs. Data are the mean value and error bars indicate the standard error of the mean difference expressed as percentage of control.
$R_{s}$ may reduce $L-R$ shunting and reduce the volume overload of the left ventricle which is found with VSD. The size of the VSD, and thus its inherent resistance, is also a major factor in controlling the L-R shunt. The larger the septal defect, the less is the resistance to flow, and thus the $R_{\mathrm{pa}} / \mathrm{R}_{\mathrm{s}}$ ratio becomes the most significant factor. In this study, we used a chronic lamb model of VSD to study the effects of three pharmacologic agents with vasodilating properties. The ventricular septal defect was large enough to elevate left atrial pressure and allow changes in the $R_{\mathrm{pa}} / R_{\mathrm{s}}$ ratio to be reflected as a change in $L-R$ shunt. The ventricular septal defect was, however, restrictive as demonstrated by peak pulmonary artery pressures being approximately $50-70 \%$ of aortic pressures. Creation of larger defects in our animals was associated with an intolerable acute mortality.

Prazosin was found to cause a selective reduction of systemic vascular resistance which increased $R_{p a} / R_{s}$ and decreased $\dot{Q}_{L-R}$. The pulmonary vascular bed is clearly responsive to $\alpha$-adrenergic agonists $(4,22)$ and these agonists can be blocked by prazosin (7). As the mechanism of action of prazosin involves competitive inhibition of $\alpha_{1}$-adrenergic receptors $(5,19)$, it appears that this type of receptor is not a major contributor to the elevated pulmonary arterial tone of lambs in the presence of a large left to right ventricular level shunt. It is possible that distension of the pulmonary arterial tree by the increased flow from the left to right shunt results in elevation of the pulmonary arteriolar vascular resistance in a manner described previously for ballooninduced distension of the pulmonary artery (16). This reflex has been shown to be unaffected by $\alpha$-adrenergic antagonists (15).

Additionally, a marked degree of pulmonary hypertension was produced in one subsequent lamb allowed to recover for 6 weeks after creation of the VSD and prior to instrumentation. This animal had systemic levels of pressure in the pulmonary artery and still showed the selective effect of prazosin on the systemic vascular bed (Fig. 5). Thus, the mechanism of pulmonary hypertension, and not the absolute levels, appears to be important in the response to prazosin. The mild increase in $R_{p a}$ with prazosin can be explained by a decrease in left atrial pressure and thus a decrease in the distention of the pulmonary vascular tree as proposed by Rudolph and Auld (26). Since the left atrial pressure was lowered, the total pulmonary resistance was altered less than the pulmonary arteriolar resistance and the total pulmonary flow was decreased slightly. However, as a result of the systemic vasodilatation, there was a decrease in the L-R shunt volume and an increase in the forward flow from the left ventricle. Prazosin, by lowering left atrial pressure and decreasing L-R shunt volume, may decrease symptoms due to a restrictive ventricular septal defect although we cannot predict if this would be true for a larger nonrestrictive VSD. The reduction noted in left atrial pressure despite an insignificant reduction in pulmonary venous return is most likely due to the reduced afterload on the left ventricle. Prazosin is also a systemic venodilator (20) and this may contribute to the reduction of left atrial pressure. However, in three lambs the right atrial pressure was measured (mean of $8 \mathrm{~mm} \mathrm{Hg}$ ) and did not change significantly following prazosin (data not shown). 
LAMB \#83I AND PRAZOSIN

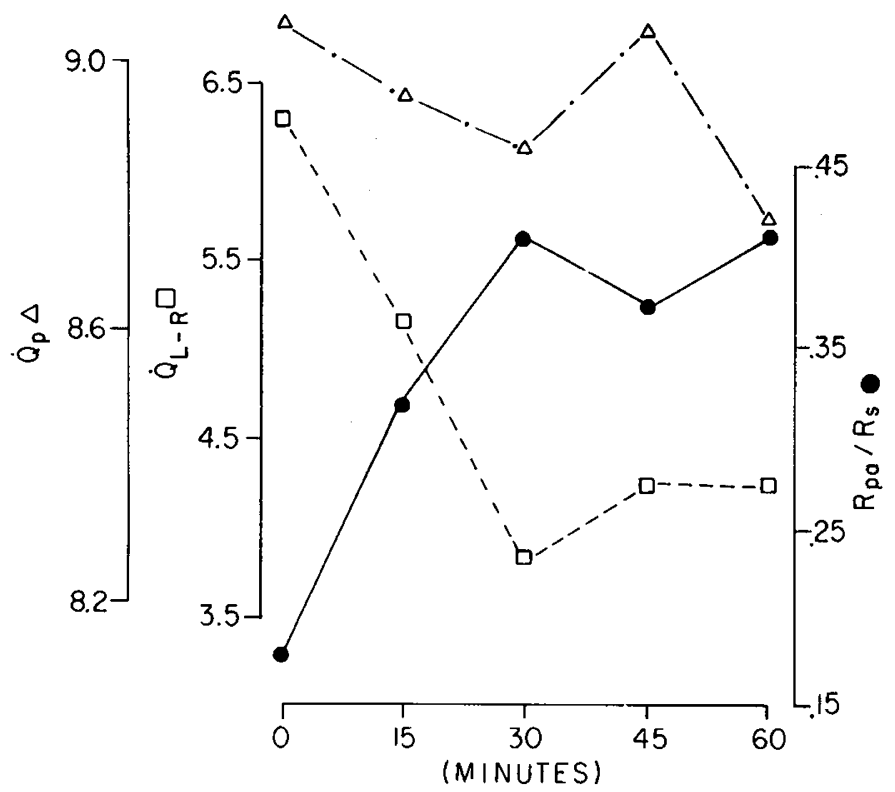

Fig. 5. The effect of prazosin on the hemodynamics of lamb 831. This animal was allowed to recover for six weeks following creation of the VSD and developed pulmonary artery pressures $\geqslant 80 \%$ of systemic pressures. The points are the actual data plotted versus time after drug administration for the pulmonary flow $\left(\mathrm{Q}_{\mathrm{p}}-\mathrm{liters} / \mathrm{min} / \mathrm{m}^{2}\right)$, the left-toright shunt $\left(\dot{Q}_{\mathrm{L}-\mathrm{R}}-\right.$ liters $\left./ \mathrm{min} / \mathrm{m}^{2}\right)$, and the $\mathrm{R}_{\mathrm{pa}} / \mathrm{R}_{\mathrm{s}}$ ratio. Data from this lamb were obtained after the original group of lambs and were not included in calculating the group data used in the other tables and figures.

Our observations support the previous findings of others describing the direct acting vasodilator hydralazine as a pulmonary vascular dilator (24). Hydralazine did not alter the $R_{p a} / R_{s}$ ratio in our studies and the pulmonary flow, systemic flow, and L-R shunt volume all increased. The reduction of $\dot{Q}_{p} / \dot{Q}_{s}$ in the absence of $R_{p a} / R_{s}$ change is likely due to the fixed resistance of the ventricular defect compared to the markedly reduced $R_{s}$. The observed tachycardia is a known response to hydralazine. Minoxidil produced effects similar to hydralazine. Minoxidil and hydralazine did not change mean left atrial pressure significantly despite a decrease in left ventricular afterload, perhaps because both agents actually increased the volume of pulmonary venous return. There was no significant vascular selectivity of action by the direct acting agents and these agents were less efficacious than prazosin.

The reduction in $R_{s}$ following prazosin was less than that seen with either hydralazine or minoxidil, yet prazosin caused a small reduction in $\mathrm{Ao}$. This was not anticipated from our preliminary studies and may relate to the lack of sympathetic overflow following vasodilatation with prazosin (12).

The dose of each drug was comparable to previously published effective doses $(8,10,23)$. The dose was determined by titrating each agent to the maximum fall in systemic resistance without changing $\overline{\mathrm{Ao}}$ in two preliminary lambs. Prazosin showed a plateau in the dose-response curve since higher doses had no greater effect on $R_{s}$. Larger doses of hydralazine or minoxidil caused a further reduction in $R_{s}$ but also caused sharp reductions in $\overline{A o}$ (data not shown). The qualitative effects of these agents are not dose dependent $(8,10,23)$ and there was no qualitative change following bolus administration in this study. Thus, it is unlikely that the observed pattern of response for each drug would be dose dependent.

Hydralazine is the only vasodilator studied in this project which has been investigated in patients with VSD. Beekman et al. (3) reported an increase in $\dot{Q}_{s}$ and a decrease in $\dot{Q}_{p} / \dot{Q}_{s}$ in infants with VSD studied in the catheterization laboratory. The effect of hydralazine was due to a decrease in $R_{s}$ despite no change in $\mathrm{R}_{\mathrm{pa}}$. However, Artman et al. (1) found that, when the pulmonary resistance was elevated in infants with atrioventricular canal defects, hydralazine caused pulmonary vasodilatation and thus did not change the L-R shunt. Nakazawa et al. (21) found that they could identify a subgroup of patients with VSD and low systemic resistance and hydralazine acted as a pulmonary vasodilator. The subgroup of patients with elevated systemic resistance did not show a pulmonary vasodilating response with hydralazine. In this study, hydralazine affected pulmonary and systemic vascular resistance similarly. The VSD in our study was restrictive as was the VSD in the clinical study of Nakazawa et al. (21); thus, the size of the VSD cannot explain the differing pattern of response to hydralazine. Several factors could explain these differences; our numbers may have been too small to identify varying patterns within subgroups and the pattern of response may vary with species. However, our data were gathered on awake nonsedated lambs. Nakazawa et al. did not specify the premedications given to their patients in the catheterization laboratory which may also affect the pattern of response. Linday et al. (17) did not demonstrate a beneficial effect of hydralazine on left to right shunts in patients of various ages and various cardiac sites of the shunt.

Whether the acute effects of prazosin seen in our study would be maintained with chronic use is unknown (2). The only report of prazosin use in children with congestive failure did not show an attenuation of effect with time (9). The effect of pharmacologic palliation of L-R shunts on possible subsequent development of pulmonary vascular occlusive disease is unknown. Our data do indicate that, in lambs with VSD, acute pharmacologic manipulation of shunt volume is feasible and of the agents studied prazosin was most effective.

Acknowledgment. Prazosin was generously supplied by Nathan Belcher, Pfizer Inc. Minoxidil was generously supplied by Thomas J. Necchio, M.D., the Upjohn Company. The authors would like to thank Linda DeWaal and Amanda Sue Kucharajek for their aid in preparing the manuscript.

\section{REFERENCES}

1. Artman M, Parrish RC, Boucek RJ, Graham TP 1982 Hemodynamic effects of acute hydralazine in infants with atrioventricular canal defects. Circulation 66:112

2. Awan NA, Mason DT 1981 Oral vasodilator therapy with prazosin in severe congestive heart failure. Am Heart J 101:695

3. Beekman RH, Rocchini AP, Rosenthal A 1982 Hemodynamic effects of hydralazine in infants with a large ventricular septal defect. Circulation $65: 523$

4. Bevan JA 1978 Response of blood vessels to sympathetic nerve stimulation. Blood Vessels 15:17

5. Cambridge D, Davey MJ, Massingham R 1977 Prazosin, a selective antagonist of post-synaptic $\alpha$-adrenoceptors. Br J Pharmacol 59:514P

6. Collins G, Calder L, Rose V, Kidd L, Keith J 1972 Ventricular septal defect: clinical and hemodynamic changes in the first five years of life. Am Heart $\mathrm{J}$ $84: 695$

7. Constantine JW, Gunnell D, Weeks RA $1980 \alpha_{1}$, and $\alpha_{2}$-vascular adrenoceptors in the dog. Eur J Pharmacol 66:281

8. Craver BN, Yonkman FF 1950 Some pharmacological properties of L-Hydrazinopthalazine, a hypotensive agent. Fed Proc 9:265

9. Dillon TR, Janos GC, Meyer RA, Benzing G, Kaplan S 1980 Vasodilator therapy for congestive heart failure. J Pediatr $96: 623$

10. Ducharme DW, Freyburger WA, Graham BE, Carlson RG 1973 Pharmacologic properties of minoxidil: a new hypotensive agent. J Pharmacol Exp Ther 184:662

11. Fisher DR; Faulkner SL, Sell CG, Graham TP, Bender HW 1978 Operative closure of isolated defects of the ventricular septum: planned delay. Ann Thorac Surg 26:351

12. Graham RM, Pettinger WA 1979 Prazosin. N Engl J Med 300:232

13. Graham TP, Bender HW, Spach MS 1977 Defects of the ventricular septum, In: Moss AJ, Adams FH, Emmanouilides GC (eds) Heart Disease in Infants, Children and Adolescents. Williams \& Wilkins Co, Baltimore

14. Hoffman JIE, Rudolph AM 1965 The natural history of ventricular septal defects in infancy. Am J Cardiol 16:634

15. Juratsch CE, Jengo JA, Laks M 1977 Role of the autonomic nervous system and pulmonary artery receptors in production of experimental pulmonary hypertension. Chest 71:265

16. Laks M, Juratsch CE, Garner D, Beazell J, Jengo J, Criley JM 1973 Chronic 
pulmonary arterial hypertension produced by distension of the main pulmonary artery (MPA) in the conscious dog. Circulation 48:114

17. Linday LA, Levin AR, Klein AA, Reidenberg MM, Engle MA 1980 Effect of vasodilators on left-to-right shunts in infants and children. Pediatr Res 14:447 18. Lusk G 1909 The Science of Nutrition. WB Saunders Co, Philadelphia

19. Miach PJ, Dausse JP, Meyer P 1978 Direct biochemical demonstration of two types of $\alpha$-adreno-receptor in rat brain. Nature 274:492

20. Miller RR, Awan NA, Maxwell KS, Mason DT 1977 Sustained reduction of cardiac impedance and preload in congestive heart failure with the antihypertensive vasodilator prazosin. N Engl J Med 297:303

21. Nakazawa M, Takao A, Chon Y, Shimizu T, Kanaya M, Momma K 1983 Significance of systemic vascular resistance in determining the hemodynamic effects of hydralazine on large ventricular septal defects. Circulation 68:420

22. Nuwayhid CR, Brinkman CS, Bevan JA, Assali NS 1975 Systemic and pulmonary hemodynamic responses to adrenergic and cholinergic agonists during fetal development. Biol Neonate 26:301
23. Oates HF, Graham RM, Stoker LM, Stokes GS 1976 Haemodynamic effects of prazosin. Arch Int Pharmacodyn 224:239

24. Rubin LJ, Peter RH 1980 Oral hydralazine therapy for primary pulmonary hypertension. N Engl J Med 302:69

25. Rudolph AM 1965 The effects of postnatal circulatory adjustments in congenital heart disease. Pediatrics 36:763

26. Rudolph AM, Auld PAM 1960 Physical factors affecting normal and serotoninconstricted pulmonary vessels. Am J Physiol 198:846

27. Steel RDG, Torrie JH 1960 Principles and Procedures of Statistics. McGrawHill Book Co, New York

28. Synhorst DP, Lauer RM, Doty DB, Brody MJ 1976 Hemodynamic effects of vasodilator agents in dogs with experimental ventricular septal defects. Circulation 54:472

29. Talner NS 1971 Congestive heart failure in the infant. Pediatr Clin Am 18:1011

30. Tanenbaum H, Pfaff W 1963 Effect of pressor amines on experimental intracardiac shunts and valvular regurgitation. Dis Chest 44:485

\title{
Studies of Lipids, Lipoproteins, and Apolipoproteins in Menkes' Disease
}

\author{
P. R. BLACKETT, D. M. LEE, D. L. DONALDSON, J. D. FESMIRE, W. Y. CHAN, \\ J. H. HOLCOMBE, AND O. M. RENNERT \\ Department of Pediatrics, University of Oklahoma Health Sciences Center, Oklahoma City, Oklahoma 73129 [P. \\ R. B., D. L. D., W. Y. C., J. H. H., O. M. R.J and Laboratory of Lipid and Lipoprotein Studies, Oklahoma \\ Medical Research Foundation, Oklahoma City, Oklahoma 73104 [D. M. L., J. D. F.]
}

\begin{abstract}
Summary
Three patients with Menkes' disease, an inherited disorder of copper transport, were studied to determine whether the copper deficiency was associated with a lipoprotein disorder. Hypocuprinemia was documented in all three cases. Two patients had severe copper and ceruloplasmin deficiencies, whereas the third patient had a less severe deficiency. Hypertriglyceridemia was observed in the first patient, and elevations in triglyceride, cholesterol, apolipoprotein B (ApoB), and apolipoprotein C-III (ApoC-III) occurred predominantly in the very low density lipoprotein fraction (VLDL). This patient had normal lipoprotein lipase activity but mild glucose intolerance. The second patient had a borderline high cholesterol level with normal plasma triglycerides and apolipoproteins, whereas the third patient appeared to have normal total cholesterol but slightly higher triglycerides with elevated plasma apolipoprotein $\mathrm{E}$ (ApoE). No striking differences were observed in the chemical composition of all lipoprotein subfractions between patients and controls except that the neutral lipid content of VLDL was higher in patients than in controls. The ApoB was initially normal in molecular weight but degraded faster than the controls during storage. The appearance of the major low density lipoprotein (LDL) fraction of the first two patients was opaque white, in contrast to clear yellow in the third patient and in the age- and diet-matched controls. This abnormal appearance of LDL in
\end{abstract}

Received December 7, 1982; accepted February 7, 1984

Reprint requests may be addressed to P. R. Blackett, M.D., University of Oklahoma, Health Sciences Center, OCMH-2B251, P.O. Box 26901, Oklahoma City, OK 73190.

This work was supported in part by Program Project HL-23181 and Grant HD16730 from the Department of Health, Education, and Welfare. these patients was associated with low plasma levels of $\beta$-carotene and ceruloplasmin. These findings suggest that decreased serum copper levels may be associated with lipid and lipoprotein abnormalities and may enhance lipid peroxidation of $L D L$ accounting for the color change. The increase in neutral lipids and the damaging effects on lipoprotein-transported substances may lead to atherosclerosis.

\section{Abbreviations}

EEG, electroencephalogram

$\mathrm{P} / \mathrm{S}$ ratio, polyunsaturated to saturated fatty acid ratio

VLDL, very low density lipoproteins

LDL, low density lipoproteins

HDL, high density lipoproteins

VHDL, very high density lipoproteins

Apo, apolipoprotein

GSH, glutathione

SDS, sodium dodecyl sulfate

Copper is an essential dietary component (13) and is known to be present in many plant and animal tissues (13). Clinical evidence of deficiency was first observed in animals and many of the clinical manifestations have been related to low tissue activities of copper enzymes such as tyrosinase, lysyl oxidase, lactase, ascorbic acid oxidase, cytochrome oxidase, uricase, monoamine oxidase, and dopamine- $\beta$-hydroxylase (31). Clinical effects of copper deficiency are manifested as widespread derangements in tissues such as skin, bone, connective tissue, red blood cells and the central nervous system. In addition, increased tortuosity of arterial wall tissues may be attributed to defective 